\title{
Gibt man Zeit, wenn man Zeit gibt?
}

Bring das Geld! - Ich habe es nicht! - Ich gebe dir 24 Stunden Zeit!, sagt der Erpresser im Fernsehkrimi zum Vater des entführten Kindes. Nun werden alle Kräfte mobilisiert, um das Geld zu beschaffen. Es gelingt mit der Kraft der Verzweiflung. - Nun nimm den Fingerhut und schöpfe das Meer aus. Ich gebe dir diese Nacht Zeit!, sagt die Hexe zum Mädchen. Da hilft auch die Kraft derVerzweiflung nicht weiter. Doch es gibt freundliche Helfer. Das Meer ist am Morgen trocken gelegt. -

Da lächelt der König mit arger List,

Und spricht nach kurzem Bedenken:

"Drei Tage will ich dir schenken.

Doch wisse! wenn sie verstrichen die Frist,

Eh du zurück mir gegeben bist,

So muss er statt deiner erblassen,

Doch dir ist die Strafe erlassen."

Es ist König Dionys, der da lächelt mit arger List; es ist der unschuldige Freund des Rebellen, der sterben soll. Der Rebell war mit »dem Dolch im Gewande", Tyrannenmord im Sinn, ertappt worden. Der König gibt ihm Zeit, die Schwester zu verheiraten. Als Geisel bleibt der Freund in königlichem Gewahrsam. Friedrich Schillers Ballade "Die Bürgschaft» entwickelt sich als grandioser und aufregend hindernisreicher Wettlauf mit der Zeit: Der Freund eilt zum Freund und wird von entfesselter Natur und wildem Räuberwesen auf Schritt und Tritt aufgehalten. Auch hier wachsen dem, der gegebene Zeit nutzen muss, ausserordentliche Kräfte zu. Und nicht nur das: die erfolgreich bewiesene Freundestreue verwandelt den Tyrannen.

Drei haben Zeit gegeben - haben sie Zeit gegeben? Sie haben Ultimaten gestellt. Wie konnten sie das? Sie verfügten über Usurpationsmacht. Sie konnten sagen:Tu dies bis dann. Damit schufen sie Sorgen. Wer Zeit gibt, schafft Sorgen. Aber die drei, die da Zeit gegeben haben, waren nicht Eigner der Zeit, sondern Wächter der Zeit. Die Freiheit der Person wurde eingeschränkt durch eine Aufgabe, die abzulehnen nicht in ihrer Macht stand und deren Ausführung nicht in ihrem planenden Belieben stand. Man gerät in die Enge der Zeit. In diesem Sinne schafft Zeit geben Sorgen. 
Gib mir Zeit, beim zweiten Mal bestehe ich die Prüfung, sagt der Student zum ungehaltenen Vater, der sich fragt, ob es dem Sohn an Talent oder Disziplin mangelt. Auch hier ist der Vater Wächter der Zeit, doch einer, der gestattet, dass der andere Zeit gewinnt. - Gib mir Zeit, sagt der Ehemann zur Frau, die sich von ihm trennen will, ich werde mich ändern (weniger abwesend sein, weniger arbeiten, weniger trinken, weniger grob zu den Kindern sein, keine Affären mehr haben ...). Leere Versprechen und schöne Worte. Die Frau ist als Wächterin nicht mächtig genug. Ihr Macht ist zu Ende, wenn sie die Trennungsabsicht rückgängig macht. Gib mir Zeit heisst:Verzichte darauf, Fakten zu schaffen.

Und doch: Zeit geben - das hat einen freundlichen Klang. Wie schön es wäre, man schenkte uns Zeit. Man meint, das ist wie ein freier Raum des Werdens, Gedeihens und Geniessens.

Aber wer kann Werden, Gedeihen und Geniessen schenken? Der Gedanke, Zeit sei uns zugemessen, es seien uns finstere und leuchtende Zeiten zugemessen, scheint eine schwer abweisbareVorstellung - auch in einer agnostischen Welt - zu sein:

Die Kräfte waren gering. Das Ziel

Lag in grosser Ferne.

Es war deutlich sichtbar, wenn auch für mich

Kaum zu erreichen. So verging meine Zeit,

die auf Erden mir gegeben war.

Bertolt Brecht weiss, was er An die Nachgeborenen schreibt. Dass er einen Kosmos beschwört, in dem eine Instanz Zeit auf Erden zu geben und zu befristen vermag. Dass es Ziele in einem Lebensweg gibt, die ein sterbendes Auge von fern erblickt wie einst Moses, der sein Volk aus einem Regime der Unterdrückung und Ausbeutung führte, aber das Gelobte Land nicht betreten konnte, so weit reichten die Kräfte selbst dieses Kraftvollen nicht. Dereinst kann es sein, Dass der Mensch dem Menschen ein Helfer ist. Das ist die Hoffnung, die das Fernsein vom Ziel ertragbarer macht.

Es kann aber auch die Stunde schlagen, ganz in die Finsternis hinein:

Ach, es ist so dunkel in des Todes Kammer,

Tönt so traurig, wenn er sich bewegt

Und nun aufhebt seinen schweren Hammer

Und die Stunde schlägt.

Kein Ziel bei Matthias Claudius, das Nachgeborene weiter verfolgen können. Nur ein Ende. Das Ende von Zeit, die gegeben war. 
Die Vorstellung einer machtvollen asymmetrischen Beziehung, in der einer Zeit geben, der andere Zeit entgegen nehmen kann, ist janusköpfig: freundlich und bedrohlich. Sie ist als freundliche Utopie die Idee einer Fülle, in der etwas beginnen und sich vollenden kann - der freundliche Blick einer Mutter auf ihr Kind, das nach den Gesetzen der eigenen Reifung gedeiht. Die Figur des `Zeit gebens hat aber andererseits ein bedrohliches Gesicht: die Frist des Mächtigen, der den anderen in eine Bringschuld nötigt. Der Gestus des Bedauerns über Lebenszeit, die als verfehlt beklagt wird, ist eine Ausdrucksform der Figur des `Zeit gebens`.

Schlecht genutzte Zeit? Muss man sich damit plagen? Der Verlorene Sohn muss es nicht. Er hat keinen Vater, den er bitten muss, ihm Zeit zu geben für Besserung, ihm eine zweite Chance einzuräumen. Er hat einen Vater, der nicht Zeit gibt, sondern Wohlwollen. Der Vater stellt Ressourcen für den Aufbruch in die Fremde zurVerfügung. Es gibt kein Versprechen, keine Verpflichtung, kein Ultimatum. Sorglos geht der junge Mann in die Welt. Zu sorglos? Er kommt abgebrannt zurück und wird willkommen geheissen. Hat er seine Zeit schlecht genutzt? Wer ist legitimiert, das zu sagen? Der Vater tadelt ihn nicht. Wer sollte es dann tun? Die Sorglosigkeit hat ihm erlaubt, den Schritt ins Freie zu tun. Die Sorgen kamen, als er in Not war. Da gehören sie hin. Sie gingen weg, als der Vater ihn freudig begrüsste. Nun kann etwas Neues entstehen. DerVater ist ein grosser und mächtiger Vater, aber es steht nicht in seiner Macht, Zeit zu geben. So lässt er es bleiben. 